\title{
Fertility department's response and experience to the global coronavirus COVID-19 pandemic
}

\author{
Dania H. Al Jaroudi*, Mona Al Dossary
}

\begin{abstract}
Department of Reproductive Endocrinology and Infertility Medicine, Obstetrics and Gynecology, King Fahad Medical
\end{abstract} City, Riyadh, Saudi Arabia

Received: 22 April 2020

Accepted: 29 May 2020

\section{*Correspondence:}

Dr. Dania H. Al Jaroudi,

E-mail: daljaroudi@kfmc.med.sa

Copyright: () the author(s), publisher and licensee Medip Academy. This is an open-access article distributed under the terms of the Creative Commons Attribution Non-Commercial License, which permits unrestricted non-commercial use, distribution, and reproduction in any medium, provided the original work is properly cited.

\begin{abstract}
WHO has asked countries to activate and scale up their emergency response mechanisms, communicate with the people to inform them about the risks and how they can protect themselves. They have encouraged find, isolate, test and treat every case and trace every contact, protect and train their health workers. Therefore, in alliance with the global response to limit the spread of the transmission of COVID-19 and in the pact of KFMC's mission, which is its dedication to provide highly specialized, evidence-based and safe health care, enhanced by education, training and research, our fertility department had taken all the measures to keep the hospital patients and staff safe from acquiring the COVID-19 by closing down its assisted reproductive services. This article will highlight the strategy taken to comply with WHO's call and highlight a fertility department's actions taken to handle patients coming for assisted reproductive treatment. This hopefully will stipulate ideas for future research and policy making.
\end{abstract}

Keywords: Assisted reproductive treatment, Coronavirus, COVID-19, Infertility, Intracytoplasmic sperm injection, In-vitro fertilization

\section{INTRODUCTION}

KFMC is considered the largest and most advanced medical complex in the Middle East with a total capacity of 1095 beds. It is located in the center of Riyadh city the capital of Kingdom of Saudi Arabia, Riyadh. This colossal medical facility was built at a cost of 2.3 billion Saudi Riyals comprises of four hospitals expected to treat annually more than 50,000 in-patients and over 600,000 out-patients. $^{1}$

The main hospital is a 459-bed hospital with specialty clinics for diagnosing and treating various diseases. Rehabilitation hospital is a 159-bed hospital offering different levels of care, including inpatient, rehabilitation, and outpatients' services. A 246-bed is available in Children's hospital and a 236-bed in women's specialized hospital. In addition to the hospitals, King Fahad medical city has 30 fully equipped operating rooms and contains the largest number of intensive care beds in the region. ${ }^{1}$

The reproductive endocrinology and infertility medicine department (REIMD) at KFMC is an established state of the art purpose-built facility located within the women's specialized hospital. In line with the mission of KFMC the department is a tertiary referral center that caters for patients referred from all over the Kingdom. The REIMD comprises the complete set up of a modern assisted conception unit including all the clinical, embryology and endocrine laboratory, ultrasound and counselling facilities. It offers a wide range of assisted conception treatments such as ovarian stimulation, intrauterine insemination, in-vitro fertilization, intracytoplasmic sperm injection and surgical sperm retrieval procedures. The department participates actively in teaching both under and postgraduate students and in research. 5 medical consultants, 5 embryologists, and 22 nurses 
currently staff the department. Our set-up also comprises a urology/andrology clinic run by a consultant urologist who has special interest in fertility and surgical sperm recovery procedures. The department has been established with the aim of setting high standards in the provision of free ART services funded by the government leading to the best possible results and excellence in the delivery of patients care. The department has CBAHI accreditation and JCI accreditation. REIMD are delighted to announce an average clinical pregnancy rate of $40 \%$ per embryo transfer for the IVF/ICSI cycles. In 2019, REIMD have completed over a thousand IVF/ICSI cycles. $^{1}$

\section{Commentary}

On Sunday morning, the $15^{\text {th }}$ of March 2020, 7:30 am patients started arriving to the REIMD to receive assisted reproductive treatment they have long waited for. Patients were coming for blood tests to start or follow up their treatment cycles, ultrasound to assess their follicles, ultrasound to assess their outcome of their embryo transfer, and patients coming for a regular first assessment screening clinic or a follow-up clinic to book for their IVF/ICSI cycles.

On that same morning, KFMC had to take strict measures in order to counteract the spread of the new coronavirus disease (COVID-19) since the infection rates started to soar in Saudi Arabia. ${ }^{2}$ Clinics were to close for nonurgent medical conditions and all elective procedures and surgeries were to be postponed as a strict measure to prevent the spread of corona virus in the hospital.

COVID-19 was characterized as a pandemic by the world health organization on March 11, 2020 (WHO) since there were 118,000 cases in more than 110 countries around the globe. ${ }^{3}$

Thus, the WHO had set a strategy to prevent the spread of the infection to save lives and reduce its impact by asking stakeholders to first, prepare and be ready, second detect, protect and treat, third, reduce transmission, and fourth, innovate and learn. ${ }^{3}$

WHO has asked countries to activate and scale up their emergency response mechanisms, communicate with the people to inform them about the risks and how they can protect themselves. They have encouraged find, isolate, test and treat every case and trace every contact, protect and train their health workers. ${ }^{3}$

Over 50 patients were waiting in the department hall to see what decision will be taken in terms of their continual of their assisted reproductive treatment.

Some were waiting for their chance to complete their IVF treatment, some wanted to know if they will have their embryos transferred, some wanted to know if they will have their oocytes aspirated.
However, with the new announcement of the pandemic and the need to limit the services for urgent cases only, there still was a deluge of patients from different regions of the kingdom of Saudi Arabia, east, west, north and south into the clinics wanting to know the fate of their cycles and their embryos.

The American College of Obstetricians and Gynecologists and the Society for maternal-fetal medicine did not declare that pregnant women were at increased risk of getting the COVID-19 infection, so hospital staff and I were faced with the dilemma whether to go ahead and complete the IVF/ICSI cycle for the patients or stop all together. Nonetheless, since the safety of the patients and staff was the major concern, the adminstration have decided to take strict measures to control the spread of the virus.

Patients, who were to start an IVF/ICSI cycle in March 2020, were advised to call after the resolution of the outbreak. Patients coming to start a frozen embryo replacement cycle were also asked for the same.

Patients coming for ultrasound folliculometry and hormonal blood test for estradiol, FSH and LH were also cancelled and were asked to stop all medication for ovarian stimulation or for preparedness of the endometrium for the frozen embryo replacement cycle.

Patients for follow up on their day 9 or 10 after ovarian stimulation were to continue if they had the follicles ready for aspiration, otherwise if the follicles were not ready for human chorionic gonadotropin trigger, the cycle was cancelled.

Patients who were ready for oocyte aspiration and who were ready for fresh or frozen embryo transfer were screened for any symptoms suggestive of COVID 19 (fever, cough, or shortness of breath) or if they had contact with known cases of the disease. All patients had screened negative and thus were asked to proceed to the procedure room one by one to complete their treatments on that day. On entry to the procedure room, patients had to put on masks and were asked to leave after 40 minutes of the procedure to give room for the next patient to be called in to avoid over crowdedness.

On the day of oocyte retrieval, if the number of eggs were equal or more than 3 , the embryos were frozen for a subsequent transfer after the resolution of outbreak. However, if the number of oocytes were less than 3 , the decision was taken to transfer the embryos on day two or three, so that by the end of the week, all patients would have their treatment decision taken and resolved and no more patients will be pushed over for the coming week.

\section{DISCUSSION}

Patients' reactions to cancellation of the treatment were different. Some had accepted hospital decision and 
understood that precautions had to be taken to minimize the chances of catching or spreading Covid-19, while others were really frustrated and livid about the whole situation and undermining the severity of the disease pandemic and its effect not only to themselves but to the whole community and were insisting to continue. Their request had to be denied. Overall infertility couples' emotional responses often include distress and loss of control. ${ }^{4}$ Hence, time was spent in counseling patients and explaining the novelty and the severity of the situation. Eventually, in the wake of the crisis, the adminstration were able to manage closing the department within five days from the time the decision was taken to stop all elective cases.

Unfortunately, for the weeks, or months to come the REIMD have decided to suspend its services until the resolution of the pandemic. The decision was taken in order to limit the spread by avoiding close contact with other patients, and since both the American College of Obstetricians and Gynecologists and the Society for maternal-fetal medicine had no clear answer on the effect of COVID-19 on pregnant women and infants in the event patients got pregnant after assisted reproduction treatment. ${ }^{5}$ Additionally, there remains a lack of specific clear recommendations to pregnant women in terms of managing and treating of COVID-19. However, since the morbidity and mortality from other respiratory infections such as influenza and SARS-CoV is higher among pregnant women, COVID-19 should also be considered a risk to them as well. ${ }^{5}$

In alliance with the global response, and guidelines to limit the spread of the transmission of COVID-19 and in the pact of KFMC's mission, which is its dedication to provide highly specialized, evidence-based and safe health care, enhanced by education, training and research, REIMD had taken all the measures to keep the hospital patients and staff safe from acquiring the COVID-19 by closing down its services. ${ }^{1,6}$

\section{CONCLUSION}

In conclusion, aggressive measures had to be taken in order to comply with the international and national regulations. Moreover, with the pandemic declaration of COVID-19 by WHO and the increased likelihood of continued spread of the virus, the individuals, institutions, and countries should prepare for the possibility of widespread community transmission and are encouraged to put all their efforts to limit such a spread and contribute to a global response. COVID-19 is presenting an unprecedented challenge, and REIMD physicians hope upon the resolution of this crisis, authors will double their effort to help all REIMD patients to accommodate their needs and keep the smiles on their faces.

\section{Funding: No funding sources \\ Conflict of interest: None declared \\ Ethical approval: Not required}

\section{REFERENCES}

1. King Fahad Medical City, hospitals and centers. Available at: www.kfmc.med.sa/EN/Pages/Home. aspx. Accessed on $17^{\text {th }}$ March 2020.

2. MOH: Four cases infected with novel coronavirus (COVID 19). The official Saudi Press Agency. Available at: https://www.spa.gov.sa/viewstory.php? lang=en\&newsid=2044475. Accessed on $17^{\text {th }}$ March 2020 .

3. WHO Director-General's opening remarks at the media briefing on COVID-19 - 11 March 2020. https://www.who.int/emergencies/diseases/novelcoronavirus-2019/events-as-they-happen. Accessed $17^{\text {th }}$ March 2020.

4. Cousineau T, Domar A. Psychological impact of infertility. Best Pract Res Clin Obstat. 2007;21:293308.

5. American College of Obstetricians and Gynecologists. Practice Advisory: Novel Coronavirus 2019 (COVID-19). Available at: https://www.acog.org/Clinical-Guidance-andPublications/Practice-Advisories?IsMobileSet=false. Accessed on $17^{\text {th }}$ March 2020.

6. Coronavirus Disease 19 (COVID-19) Guidelines February 2020. Available at: https://www.moh.gov.sa/CCC/healthp/regulations/D ocuments/Coronavirus\%20Disease\%202019\%20Gui delines\%20v1.1.pdf. Accessed on 17 ${ }^{\text {th }}$ March 2020.

Cite this article as: Al Jaroudi D, Al Dossary M. Fertility department's response and experience to the global coronavirus COVID-19 pandemic. Int J Reprod Contracept Obstet Gynecol 2020;9:3103-5. 